VOL. 7

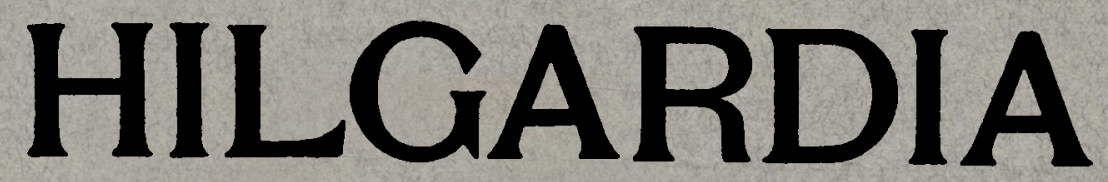

A Journal of Agricultural Science PUBLISHED BY THE

California Agricultural Experiment Station

\title{
CONTENTS
}

Injurious Effects of Manganese and Iron Deficiencies on the Growth of Citrus
A. R. C. HAAS

UNIVERSITY OF CALIFORNIA PRINTING OFFICE 
The titles of the Technical Papers of the Calffornia Agricultural Experiment 8tation, which HILGARDIA replaces, and copies of which may be had on application to the Publications Secretary, Agricultural Experinent 8tation, Berkeley, are as follows:

4. Effect of Sodium Chlorid and Calcium Chlorid upon Growth and Composition of Young Orange Trees, by H. S. Reed and A. R. C. Hsas. April, 1923.

5. Citrus Blast and Black Pit, by F. 8. Fawcett, W. T. Horne, and A. F. Camp. May, 1923.

6. A Study of Deciduous Fruit Tree Rootstocks with Special Reference to Their Identification, by Myer J. Heppner. June, 1923.

7. A Study of the Darkening of Apple Tissue, by E. L. Overholser and W. $\mathbf{V}$. Cruess. June, 1923.

8. Effect of Salts on the Intake of Inorganic Elements and on the Buffer System of the Plant, by D. R. Hoagland and J. C. Martin. July, 1923.

9. Experiments on the Reclamation of Alkali Soils by Leaching with Water and Gypsum, by P. L. Hibbard. August, 1923.

10. The Seasonal Variation of the soll Moisture in a Walnut Grove in Relation to the Hygroscopic Coefflcient, by L. D. Batchelor and H. S. Reed. Beptember, 1823.

11. Studles on the Effects of Sodinm, Potassium, and Calcium on Young Orange Trees, by H. S. Reed and A. R. O. Haas. October, 1923.

12. The Effect of the Plant on the Reaction of the Culture Solution, by D. R. Hoagland. November, 1923.

14. The Respiration of Potato Tubers in Relation to the Occurrence of Blackheart, by J. P. Bennett and E. T. Bartholomew. January, 1824.

16. The Moisture Equivalent as Influenced by the Amount of Soll Used in tta Determination, by F. J. Veihmeyer, 0 . W. Israelsen and J. P. Conrad. September, 1924.

17. Nutrient and Toxic Effects of Certain Ions on Citrus and Walnut Trees with Especial Reference to the Concentration and $\mathrm{Ph}$ of the Medium, by H. S. Reed and A. R. C. Haas. October, 1924.

18. Factors Influencing the Rate of Germination of the 8eed of Asparagus Offlelnalis, by H. A. Borthwick. March, 1925.

19. The Relation of the subcutaneous Administration of Iiving Bacterium Abortum to the Immunity and Carrier Problem of Bovine Infectious Abortion, by George H. Hart and Jacob Traum. Aprll, 1925.

20. A Study of the Conductive Tyssues in Shoots of the Bartlett Pear and the Relationship of Food Movement to Dominance of the Apical Buds, by Frank E. Cardner. Aprll, 1926. 


\title{
HILGARDIA
}

A JOURNAL OF AGRICULTURAL SCIENCE

PUBLISHED BY THE

CALIFORNIA AGRICULTURAL EXPERIMENT STATION

VOL. 7

NOVEMBER, 1932

No. 4

\section{INJURIOUS EFFECTS OF MANGANESE AND IRON DEFICIENCIES ON THE GROWTH OF CITRUS ${ }^{1,2}$}

\author{
A. R. C. HAAS 3
}

\section{INTRODUCTION}

The presence of a small amount of manganese is known to be essential for chlorophyll formation in certain plants, while the presence of an excess is destructive to chlorophyll. It is believed that neither iron nor manganese is a constituent of chlorophyll. Iron is the only element commonly spoken of as being a catalyzer of chlorophyll formation. The importance of manganese in chlorophyll catalysis is becoming increasingly more evident, which is believed to be indirectly due to its action upon the iron of the cells. Interest in these elements is increased because very little is known regarding their effects on the growth of citrus, and especially of their possible bearing on the mottle-leaf problem.

With citrus in sand or solution cultures no manganese-deficiency symptoms could be obtained when so-called "chemically pure" iron was used except in cases where a minimum of iron was used with cultures of rapidly growing 2 to 3-year-old trees. Chemical analysis showed that every source of iron available for culture solutions was contaminated with manganese to a greater or lesser extent, and that until manganese-free iron was prepared it was impossible to differentiate between the effects of deficiencies of iron and manganese. In solution cultures with seedlings, in short-term experiments with orange

1 Received for publication April 21, 1932.

2 Paper No. 271, University of California Graduate School of Tropical Agriculture and Citrus Experiment Station, Riverside, California.

3 Associate Plant Physiologist in the Experiment Station. 
or lemon cuttings, or in longer-term experiments in which larger plants are obtained in solution cultures where generous amounts of iron citrate or tartrate are used, no manganese-deficiency symptoms were evident because of the manganese contaminations in the iron supply.

The writer has always added manganese to culture solutions used for citrus, more as a matter of good practice than for any other reason. With manganese as an unknown contamination in the iron supply it made no difference whether manganese was added or was omitted; hence the belief that its presence was of no consequence.

An investigation was therefore undertaken to determine whether manganese and iron were necessary for healthy growth in citrus, and if so, the symptoms of their deficiencies in artificial solution cultures, their relation to one another, and their possible bearing on the mottleleaf problem.

\section{REVIEW OF LITERATURE}

In a study of the effect of manganese, copper, and zinc, McHargue, ${ }^{(17)}$ McHargue and Shedd, ${ }^{(19)}$ and McHargue and Calfee ${ }^{(18)}$ have recently reported concentrations of these elements as stimulating greater growth of certain plants.

Manganese deficiency in pure quartz sand cultures of annual plants soon resulted (Miller ${ }^{(22)}$ ) in a chlorotic condition, but healthy growth was quickly resumed upon adding manganese sulfate. Samuel and Piper ${ }^{(24)}$ concluded that gray speck disease of oats is due to a deficiency of manganese and made the suggestion that possibly pecan rosette, mottle-leaf of citrus, and walnut yellows are manganese-deficiency diseases.

Bishop $^{(1)}$ reported that when the manganese supply was exhausted, the plants he used either died or remained dwarfed. A manganese deficiency caused yellow spots on the new leaves, and the leaves were unable to synthesize chlorophyll. Chlorosis or yellow spots also occurred when an excess of manganese was used. Low as well as high manganese caused a loss of chlorophyll. He was unable to confirm the results of Johnson, ${ }^{(12)}$ who found that manganese depressed the iron assimilation. Bishop ${ }^{(1)}$ confirmed the results obtained by Kelley, ${ }^{(13)}$ who found that manganese increases the calcium in plants, which supposedly counteracts the toxicity of the high manganese concentrations. The chlorosis of pineapple leaves on plants grown on manganese soils is considered by McGeorge $e^{(16)}$ to be due to a greater assimilation of lime, indirectly caused by the presence of manganese in excessive amounts in the soil. 
McLean, ${ }^{(20)}$ McLean and Gilbert, ${ }^{(21)}$ and Gilbert and McLean ${ }^{(5)}$ report the curing of lime-induced chlorosis of spinach and other plants by feeding the plants manganese through the stomata. External applications of copper and manganese on certain chlorotic plants of the Florida Everglades have been found by Bryan ${ }^{(2)}$ to have a stimulating effect upon growth. The application of manganese to the soil has corrected chlorosis of soy beans in various soil types on the lower Coastal Plain of North Carolina (Willis ${ }^{(26)}$ and $\mathrm{Mann}^{(15)}$ ). Lee and McHargue $^{(14)}$ found that Pahala-blighted leaves of sugar cane had a greatly reduced manganese content but no decrease of iron. An increase in soil acidity, the addition of manganese to the soil, or the application of manganese to the leaves soon resulted in recovery of the blighted leaves.

Manganese is essential, but will not replace iron in the growth of Chlorella sp., according to Hopkins. ${ }^{(9)}$ The function of manganese is suggested as being that of a controlling agent in maintaining a suitable ratio of ferrous to ferric iron in the culture or in the cell. He found that in vitro, manganese tends to prevent the reduction of ferric to ferrous iron by sodium citrate. Cultures of yeasts indicated that the reduction of the iron by the yeast organism tends to be prevented by the presence of manganese. Sufficient manganese is considered essential in order to insure the reoxidation of the iron after its reduction by the organism. Excessive manganese either results in too high a concentration of ferric ions or prevents the reduction to the ferrous state by the organism. Ingalls and Shive ${ }^{(11)}$ have reported the distribution of iron in plants as being related to the H-ion concentration of the tissue fluids.

In their studies on the growth of Lemna it was found by Clark and Fly ${ }^{(3)}$ that manganese was not essential in the nutrition of Lemna major. Since the appearance of their paper, Hopkins ${ }^{(10)}$ has shown that manganese is an essential element for healthy growth of Lemna. Richards ${ }^{(23)}$ has reported that soil conditions have little to do with the manganese content of foodstuffs.

The toxic action of an excess of manganese on citrus in sand culture has recently been studied by Haas ${ }^{(6)}$. Mottling as well as chlorosis resulted, and in severe cases a characteristic gum or resin spot appeared in the leaves. 


\section{METHODS}

The present work employed rooted cuttings of Rough lemon, lemon (Citrus limonia Osbeck), and orange (Citrus sinensis Osbeck) in solution cultures. These were grown in the glasshouse in shallow enameled pans through a period of 12 or more months. Budded citrus trees in large sand cultures were used to supplement experiments conducted with solution cultures.

The cuttings were grown in Hoagland's solution modified so as to contain double the concentration of calcium nitrate. The concentration of ions in this solution, in parts per million, was as follows:

$\begin{array}{ccccccccc}\mathrm{Na} & \mathrm{K} & \mathrm{Ca} & \mathrm{Mg} & \mathrm{NO}_{3} & \mathrm{Cl} & \mathrm{SO}_{4} & \mathrm{PO}_{4} & \text { Total } \\ 7 & 185 & 318 & 54 & 1,211 & 10 & 216 & 105 & 2,106\end{array}$

Two and one-half p.p.m. of zine as zine nitrate and 0.1 p.p.m. of boron as boric acid were used in all cultures. To this solution were added various ions such as iron, manganese, silicic acid, etc., as the experiments required. Manganese was omitted in some cultures and iron in others.

"A-Y" $\mathrm{Y}$ " was used as a source of manganese in certain cultures, while in others this same solution was used with manganese omitted. Manganese-free iron was prepared electrolytically with an apparatus that consisted of a glass battery jar in which was placed a porous clay cell or cylinder. A bar of iron placed in the clay cell served as the positive electrode, while a heavy platinum wire fused into a glass tube containing mercury served as the negative electrode. Iron sulfate solution prepared in a manner similar to that of Samuel and Piper ${ }^{(24)}$ filled the jar and clay cell. An auto battery served as a source of direct current. In this way, a large quantity of manganese-free iron citrate was prepared.

It was found to be more beneficial to the plant to renew the evaporated water daily than to keep the level of the solution constant. A

4 " $\mathrm{A}-\mathrm{Z}$ "' stock solution contains the following amounts of salts in 18 liters: 15.9408 grams $\mathrm{Al}_{2}\left(\mathrm{SO}_{4}\right)_{3} \cdot 18 \mathrm{H}_{2} \mathrm{O}, 1.6953$ grams KI, 5.1787 grams $\mathrm{Ti}_{2}\left(\mathrm{SO}_{4}\right)_{3}, 1.9300$ grams $\mathrm{KBr}, 4.1959$ grams $\mathrm{Sr}\left(\mathrm{NO}_{3}\right)_{2} \cdot 4 \mathrm{H}_{2} \mathrm{O}, 22.9709$ grams $\mathrm{LiNO}_{3} \cdot 3 \mathrm{H}_{2} \mathrm{O}, 5.2628$ grams $\mathrm{MnSO}_{4} \cdot 4 \mathrm{H}_{2} \mathrm{O}, 7.3071$ grams $\mathrm{H}_{3} \mathrm{BO}_{3}$, and 5.7503 grams $\mathrm{NH}_{4} \mathrm{NO}_{3}$. When 25 ce of " $\mathrm{A}-\mathrm{Z}$ " ' stock solution is used in 18 liters of Hoagland's solution, a concentration of 0.1 p.p.m. of the following is obtained: aluminum, iodine, titanium, bromine, strontium, lithium, manganese, boron, and ammonium. The distilled water is obtained from a tin-lined copper still and stored in a copper tank lined with an electrolytic covering of tin. It is possible, therefore, that the distilled water contains an extremely small amount of copper. Additional copper was therefore not added to the culture solution. When lithium is omitted " $\mathrm{A}-\mathrm{Z}$ " is referred to as " $\mathrm{A}-\mathrm{Y}$." 
leveling device (see Haas, ${ }^{(6)}$ page 487 ) was used only when it was not possible to fill the culture vessel during a 24-hour period. No aeration of the culture solution was carried on except for the renewal of oxygen

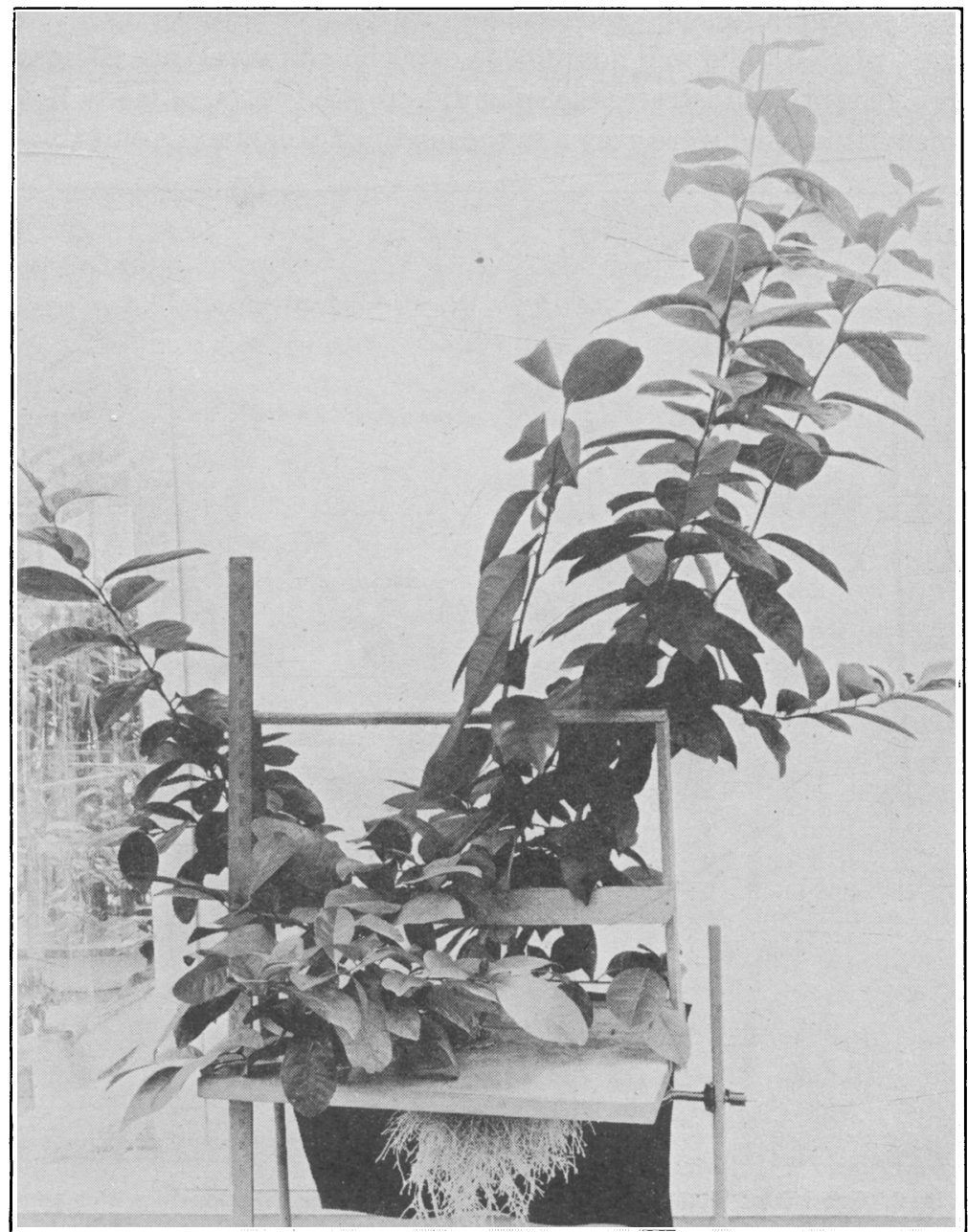

Fig. 1. Rough-lemon cutting in a culture solution to which were added manganese-free iron, zinc, silicic acid, and "A-Y." The character of the growth indicates the suitability of solution cultures for nutrition deficiency studies.

added in the distilled water containing iron. The refilling of the culture vessels daily prevented undue salt-concentration effects and also retarded the warming of the solution during periods of high temperature. Culture pans are now being sunk in sand that can be kept moist in shallow galvanized-iron pans. 


\section{EFFECTS OF CULTURE SOLUTIONS ON GROWTH}

Rough-lemon, lemon, and orange cuttings, because of their rapid growth, proved to be well adapted to experiments involving manganese or iron. Figure 1 illustrates the splendid growth typical of many Roughlemon cuttings that were grown in the modified Hoagland's culture solu-

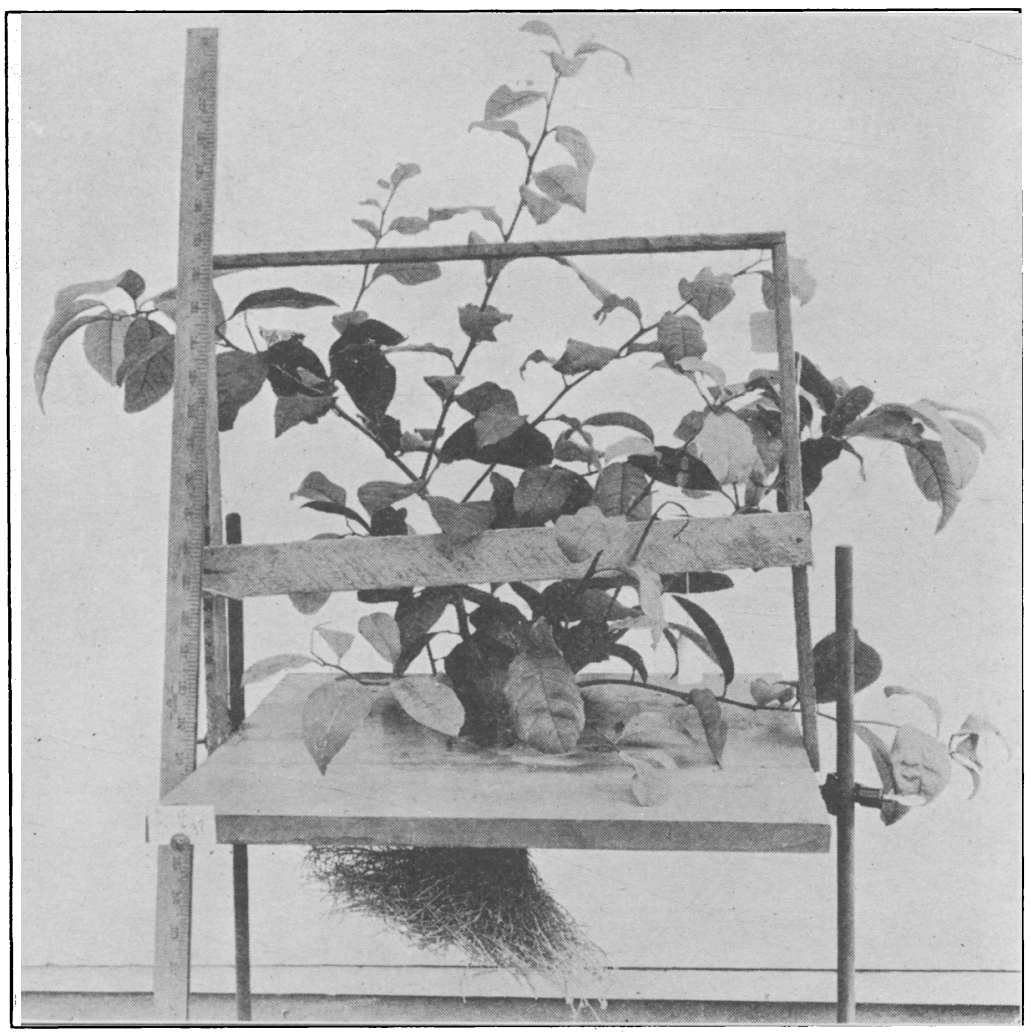

Fig. 2. Growth of Rough-lemon cuttings in a culture solution to which purified iron, zine, and manganese-free " $\mathrm{A}-\mathrm{Y}$ " were added. Several young shoots have lost all their young leaves and have died. See figure 3.

tion to which was added manganese-free iron, zinc, silicic acid, and "A-Y." Several parts per million of manganese-free iron were added two to three times each week.

Cuttings in solution cultures have successfully withstood maximum glasshouse temperatures as high as $109^{\circ} \mathrm{F}$ and culture-solution temperatures as high as $91^{\circ} \mathrm{F}$. The cutting shown in figure 1 transpired 18.5 
liters during 19 days when the daily maximum glasshouse temperature varied from $92^{\circ}$ to $100^{\circ}$ and the solution temperature from $71^{\circ}$ to $82^{\circ}$. Another cutting transpired 33.0 liters during 45 days when the daily maximum glasshouse temperature varied from $91^{\circ}$ to $109^{\circ}$ and the daytime solution temperature from $73^{\circ}$ to $91^{\circ}$. The transpiration per unit area was not calculated, but the figures indicate the absorptive capacity of the root system. The roots subjected to such temperatures retained a healthy white color, as may be seen in figure 1; the leaves were dark green and the shoots vigorous.

Effects of Manganese Deficiency on Growth of Rough Lemon.When manganese was omitted from the culture solution the growth of Rough-lemon cuttings was severely restricted and there was a marked abscission of young leaves that were unable to attain full size. Figures 2 and 3 show two Rough-lemon cuttings 6 months after they were transferred from the control solution to one lacking manganese. The leaves were yellowish-green (chlorotic), as though they were in need of iron, even though manganese-free iron was added two or three times a week.

This might be taken to indicate, as Hopkins has suggested, that the leaves were unable to reoxidize the iron after its reduction by the plant. Data given later show that a deficiency of manganese did not prevent the leaves from obtaining large amounts of iron, but it is likely that the iron was of little use to the leaves for the formation of chlorophyll. It is striking that during the months of manganese deficiency the roots remained in an excellent condition, ready to start growth upon the addition of manganese to the culture solution.

Recovery of Growth of Rough Lemon upon Addition of Manganese to Manganese-deficient Cultures.-The quick response of the growth of manganese-deficient Rough-lemon cuttings upon the addition of manganese may be seen in figures 4 and 5 . The addition of 1 p.p.m. of manganese as manganese sulfate to the culture solution was followed by a new cycle of growth (fig. 5) almost simultaneously throughout the entire top. The new leaves were deep green in color.

Effects of Manganese Excess on Growth of Rough Lemon and on Orange.-Chlorosis in citrus was produced not only by a deficiency of manganese, but also by an excess. Chlorosis of leaves of Rough-lemon cuttings occurred when as little as 5 p.p.m. of manganese was added two or three times a week. The excessive manganese made the roots dark brown, and the new leaves became successively more chlorotic with each new cycle of growth (fig. 6). Here chlorosis is associated with excessive manganese even when generous supplies of manganese-free iron were added. The culture solution was then renewed and the total manganese concentration was limited to 5 p.p.m. Iron additions were 


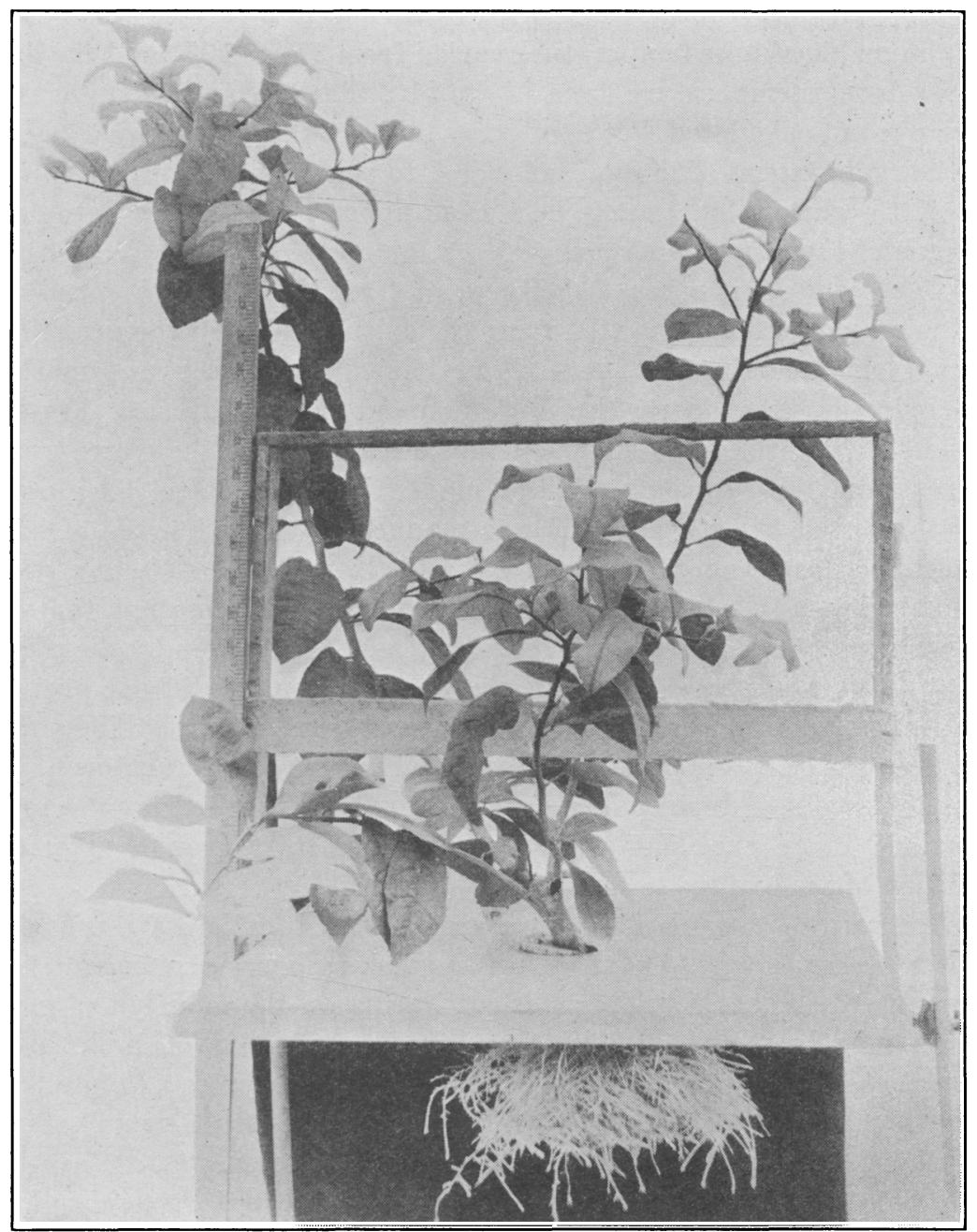

Fig. 3. Growth of Rough-lemon euttings in a culture solution to which purified iron, zinc, and manganese-free " $\mathrm{A}-\mathrm{Y}$ ", were added. This plant was larger than that shown in figure 2 when the cuttings were removed from the control solution and placed in the manganese-free solution. Then for 6 months, growth of the tops was at a standstill. The roots, however, maintained a white healthy appearance during this period. 


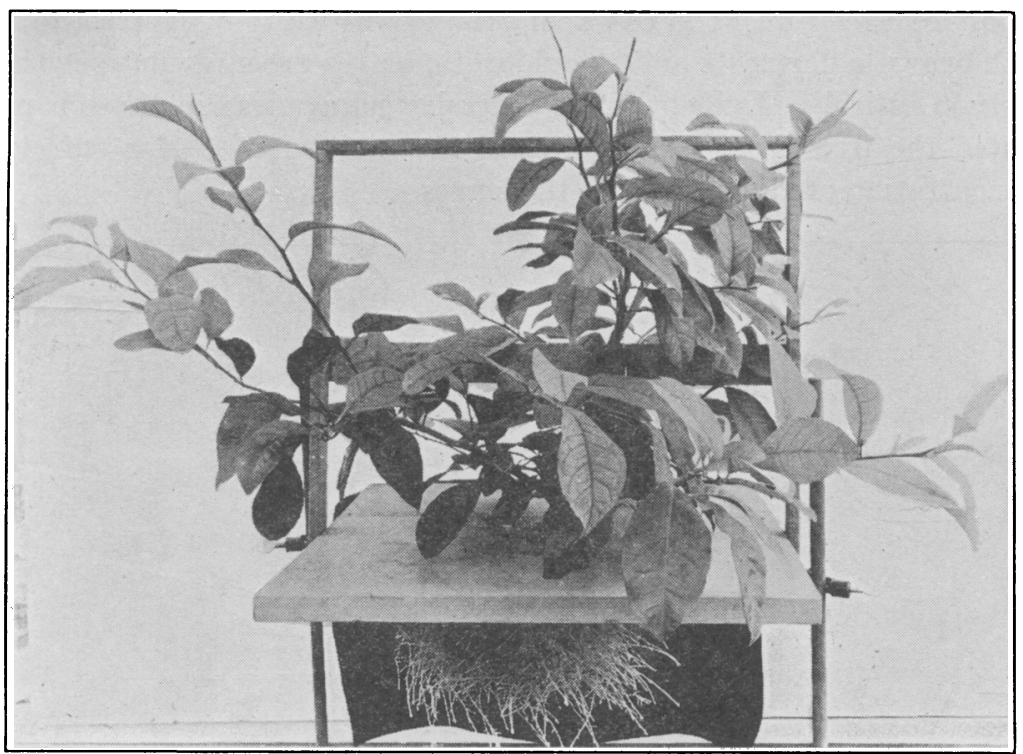

Fig. 4. Rough-lemon cutting after 6 months in a culture solution containing iron but no manganese. The manganese-deficient leaves of the last growth cycle were removed for analysis just prior to the addition of the manganese to the culture solution. Figure 5 shows the same cutting after manganese had been supplied.

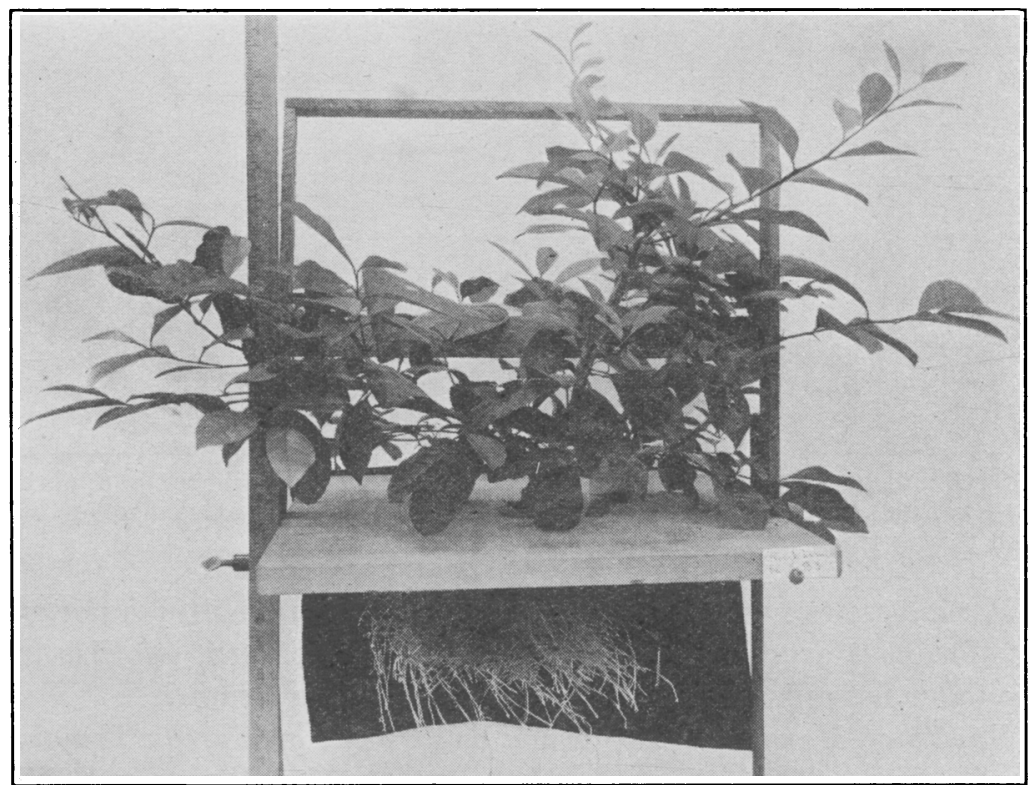

Fig. 5. Same cutting as in figure 4, 29 days after manganese was supplied. 
continued as before. The new root growth was white in contrast to the dark-brown older roots and the chlorotic leaves greened up somewhat, but not entirely. Evidently the excessive manganese in the top prevented the iron from functioning in the maintenance of a sufficient concentration of chlorophyll in the leaves.

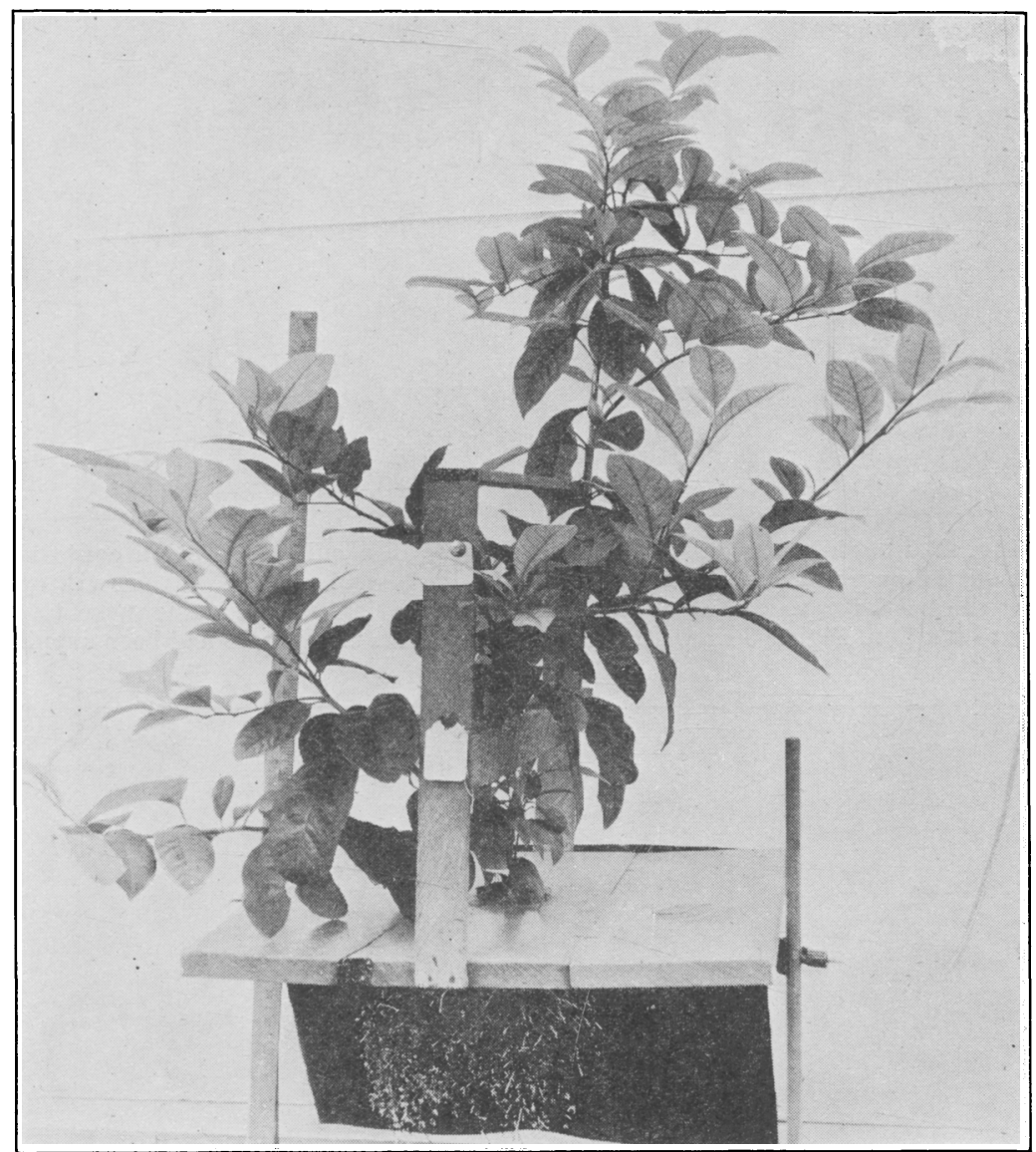

Fig. 6. Rough-lemon cutting grown in a culture solution to which boron, purified iron, zinc, and manganese sulfate were added. Five p.p.m. of manganese were added two or three times a week.

Manganese excess on young orange trees in sand cultures not only brought about degrees of mottling, chlorosis, and burn, but also produced gum or resin spots on the leaves, as shown in figure 7 .

Effects of Manganese Deficiency on Growth of Eureka Lemon.Eureka-lemon cuttings were unable to produce healthy growth when in a culture solution lacking manganese. Figure $8 A$ shows the spotted 
leaves in the center of the top and the lack of new growth. The roots were in an excellent condition. Some of the leaves were then removed for analysis. Twenty-nine days after the culture was given manganese, the growth was as seen in figure $8 B$.

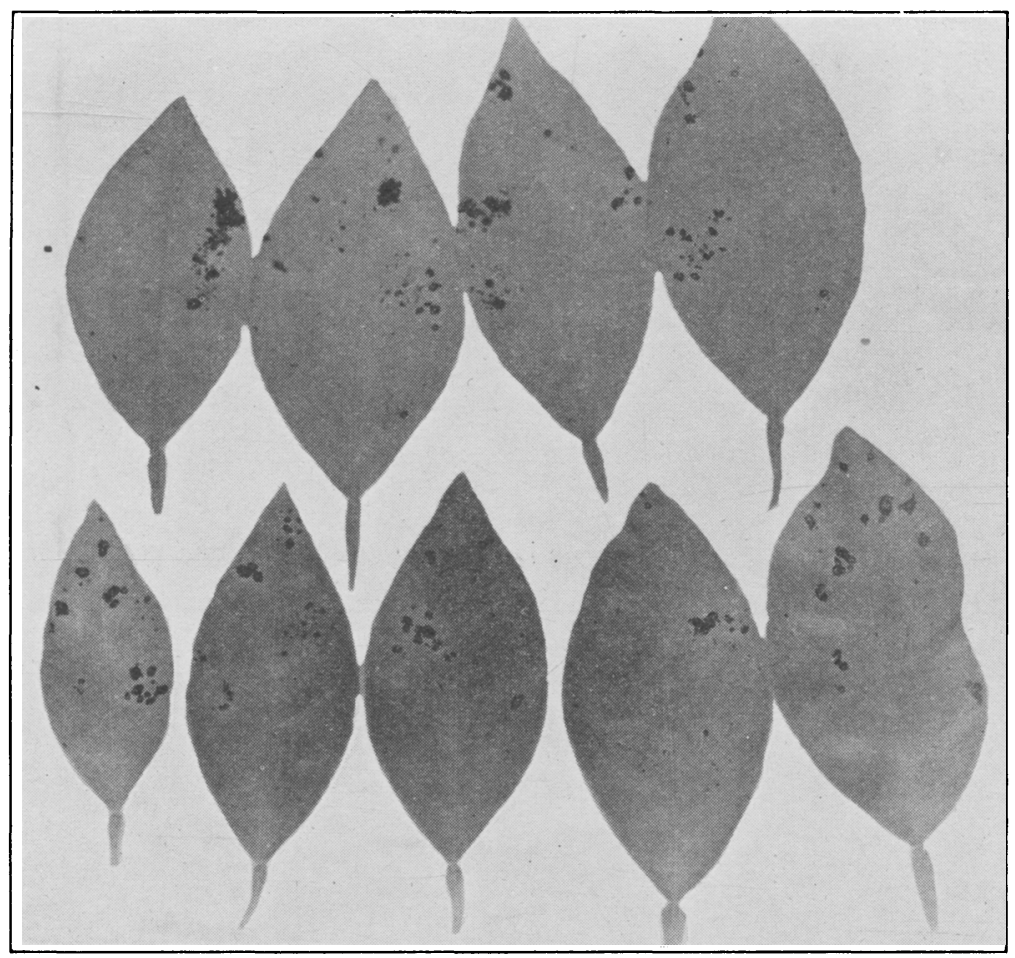

Fig. 7. Dark-green Valencia-orange leaves showing raised resinous areas as one effect of excessive manganese. Upper row: ventral leaf surface; lower row: dorsal leaf surface. The leaves were collected from trees in sand cultures that received Hoagland's solution modified so as to contain 100 p.p.m. of manganese as manganese sulfate until toxicity was evident, after which the manganese concentration was reduced to 0.1 p.p.m.

The addition of 0.1 p.p.m. of manganese brought about growth which manganese-free iron was unable to do. Eureka-lemon cuttings in a manganese-free culture solution apparently continue to grow until the available manganese within the plant becomes inadequate for the new leaves to reach full size at maturity. Leaves that attain full size before growth ceases are spotted, and yellowish green; they are not prematurely abscissed. When leaves are unable to reach full size they absciss prematurely. Practically all of the retained leaves of the last growth cycle are unhealthy. 

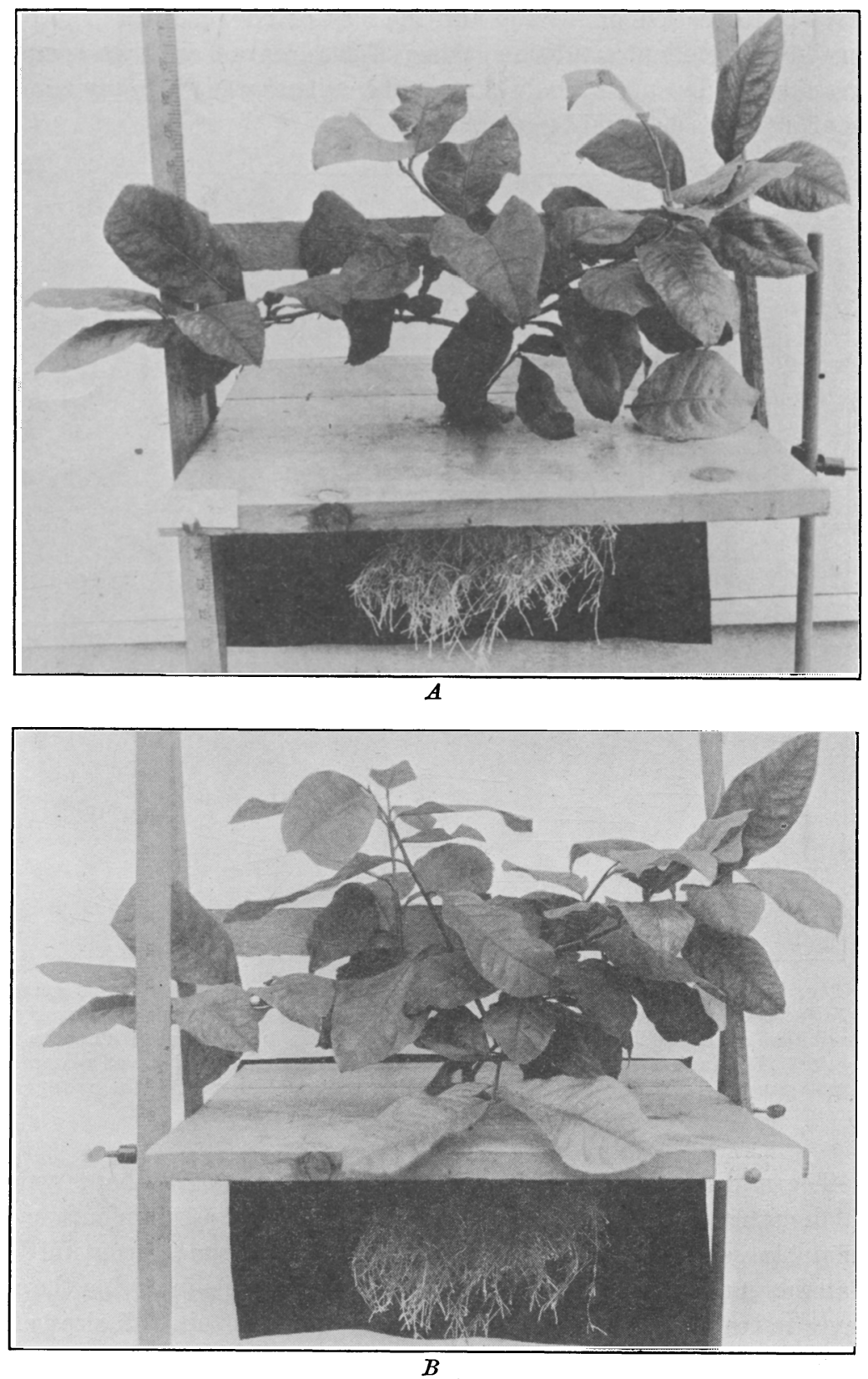

Fig. 8. Eureka-lemon cuttings: $A$, after 6 months in a culture solution containing iron but no manganese; $B$, same cutting 29 days after manganese was supplied. The manganese-deficient leaves of the last growth cycle in $A$ were removed for analysis just prior to the addition of the manganese to the culture solution. 
Dark-green, healthy growth can be retained in successive growth cycles when manganese is not deficient, as seen in the control Eurekalemon cutting shown in figure 9. Each of several cuttings such as that

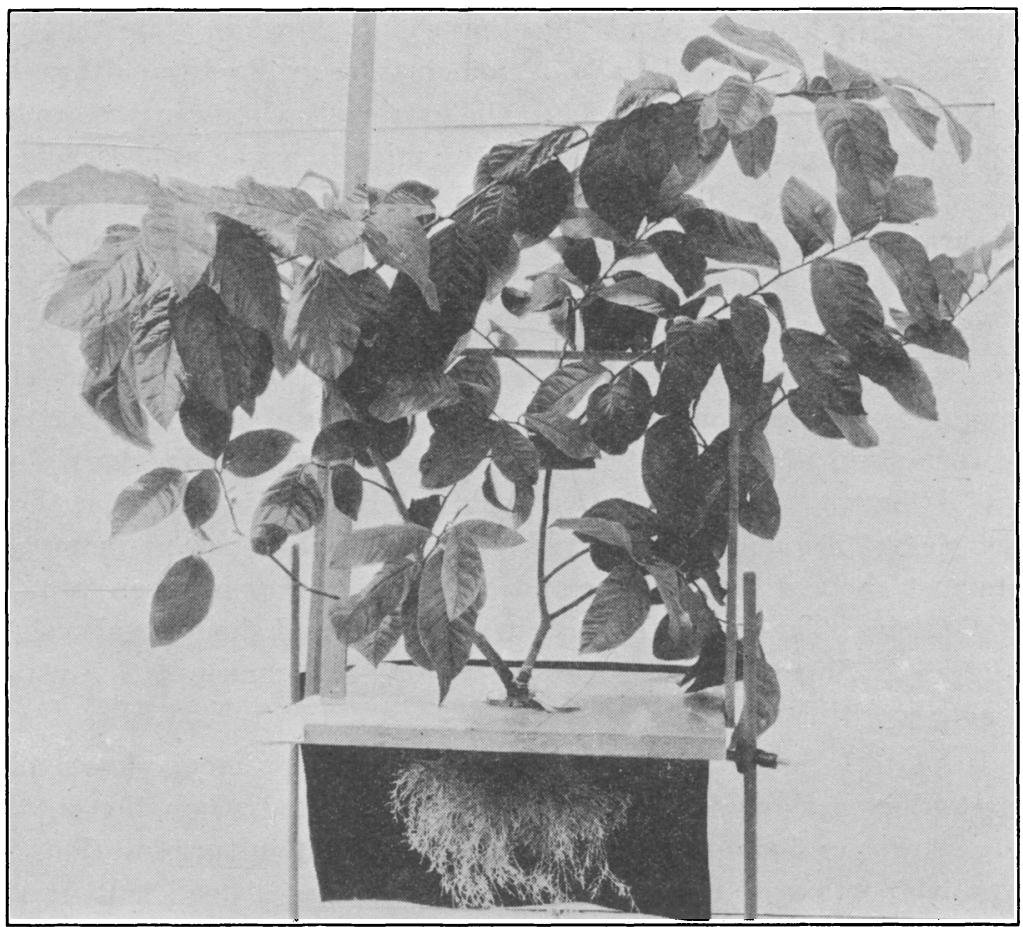

Fig. 9. Control Eureka-lemon cutting grown in a culture solution containing boron, zine, purified iron, and 0.1 p.p.m. manganese.

shown in figure 9 were carrying three or four lemons of unusually large size.

The leaves of manganese-deficient Eureka-lemon cuttings become chlorotic, and the shoots bearing them are usually dwarfed. Plate 4, figure 1 shows a branch of a Eureka-lemon cutting grown in a manganese-free culture solution. The new growth following the omission of manganese is chlorotic and the leaves are spotted. Many of the old leaves on the branch are dark green because the culture had previously been supplied with iron and manganese in order to bring the cuttings into excellent condition prior to the manganese-deficiency experiment.

The absence of manganese produces characteristic effects on both leaves and shoots of lemon and Rough-lemon cuttings. These effects consist of curling and premature abscission of young leaves that are 
unable to attain full size. In plate 1 , figure 1 , the second shoot from the right is a young Eureka-lemon shoot taken from a cutting grown in a culture solution containing manganese. The young leaves of this control shoot soon were well expanded, both halves of a leaf being in the same plane and of a healthy color. The other shoots shown in plate 1, figure 1 were taken from several Eureka-lemon cuttings grown in a culture solution deficient in manganese. Even the extremely young leaves are seen to be either curved ventrally along the midrib or the apical region $i$; recurved ventrally. The manganese-deficient leaves are unhealthy in appearance, and a slow death of the defoliated shoot usually follows the abscission of the leaves.

Nature of Manganese-Deficiency Gum Spots on Lemon Leaves and Shoots.-The shoots from which immature leaves of cuttings grown in manganese-deficient cultures have abscissed are of interest because of the formation of gum that may take place on them. To the right in plate 1, figure 2 are shown two such defoliated Rough-lemon shoots. Such shoots frequently are curved and in the figure show a gummy exudate just above a petiole scar and another midway between two such petiole scars. The characteristic curve of the dead shoots is also shown in figure 2. Shoots killed as a result of high salt concentration usually do not show this curvature.

In plate 1, figure 2 are also shown other Rough-lemon shoots and a Eureka-lemon shoot that were severely defoliated when the cuttings were grown for 6 months in a manganese-deficient culture solution. The terminal portion of the Eureka-lemon shoot has a dead tip. It is of unusual interest that this portion has a gummy or resinous excrescence along the surface like that found in cases of exanthema, or die-back, on citrus in the field. Gum blisters or the orifices of blisters that have already exuded gum may be seen on the Rough-lemon shoots. In exanthema the gum blisters are usually found in the region of petiolar attachment, while here they are scattered indiscriminately along the shoot.

The gum blisters occur in the region of the young xylem, the cambium, and the phloem tissues. Some blisters may enlarge and not break open while others force a passage of the gum to the surface of the shoot. Figure 10 shows a cross section of a gum blister on a shoot of a Roughlemon cutting grown 6 months in a culture solution lacking manganese. The passageway of the gum from the gum pocket to the surface of the shoot is seen to be a direct one. Neither the vessels nor the wood parenchyma cells are plugged with gum.

The effect of manganese deficiency is evident not only in the young shoots and immature leaves that absciss, but also in the spotted leaves 


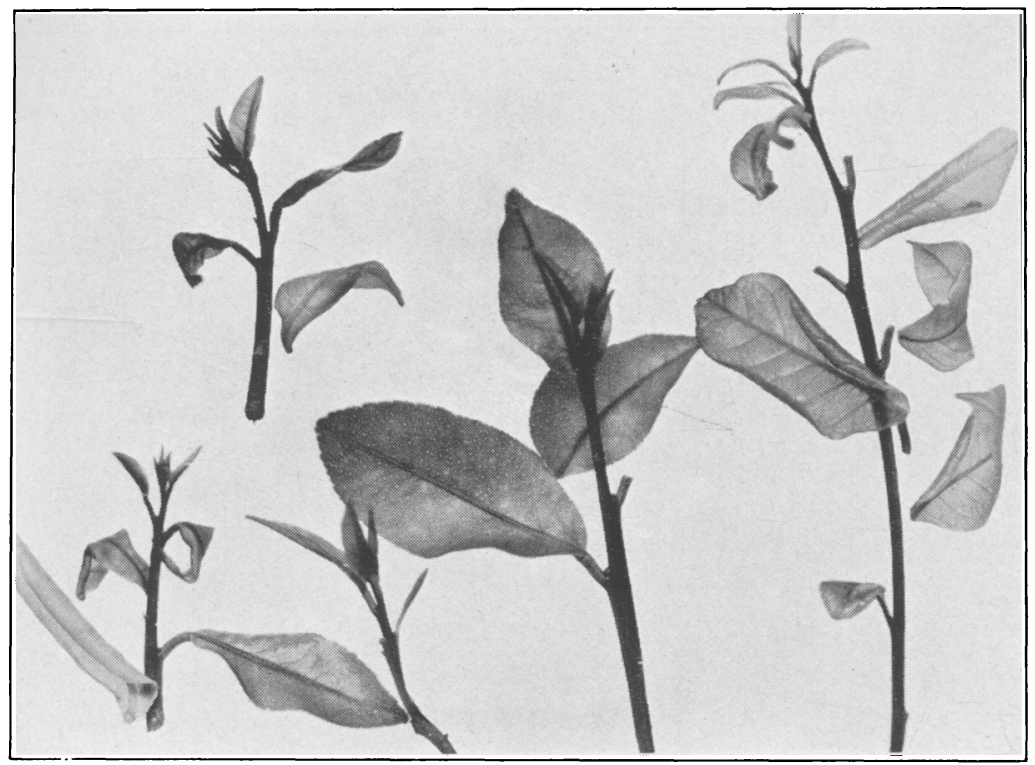

Fig. 1. Growth of young Eureka-lemon shoots taken from cuttings. The control, the second shoot from the right, was taken from a cutting grown 6 months in a culture solution containing boron, zinc, purified iron, and manganese. One of the leaves was broken off in covering the shoots with glass in taking the photograph. The other shoots were taken from cuttings grown in culture solutions similar to the control, but lacking manganese. Many of the leaves of these manganese-deficient shoots have curled and abscissed. The small spots on all leaves represent the oil glands, which are not affected by a manganese deficiency.

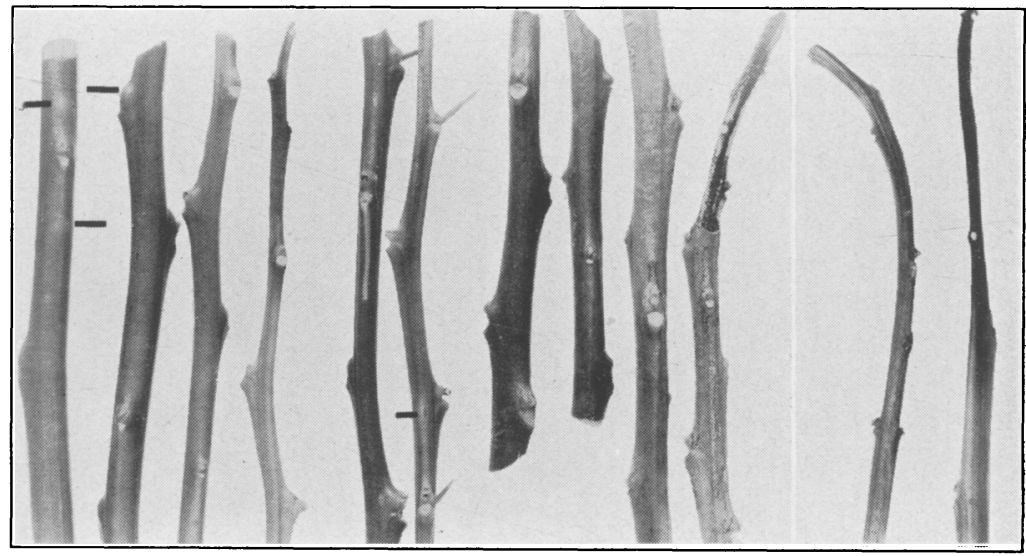

Fig. 2. Defoliated shoots taken from cuttings grown 6 months in a culture solution containing zinc, purified iron, and "A-Y" lacking manganese. The two Rough-lemon shoots to the right show internodal exudates of gum. The third, fourth, fifth, and sixth pieces from the right represent one Eureka-lemon shoot. Note the resinous excrescence near the tip. The next two pieces represent one shoot, and the four pieces to the left another shoot taken from Rough-lemon cuttings. The black lines point to gum pockets. 


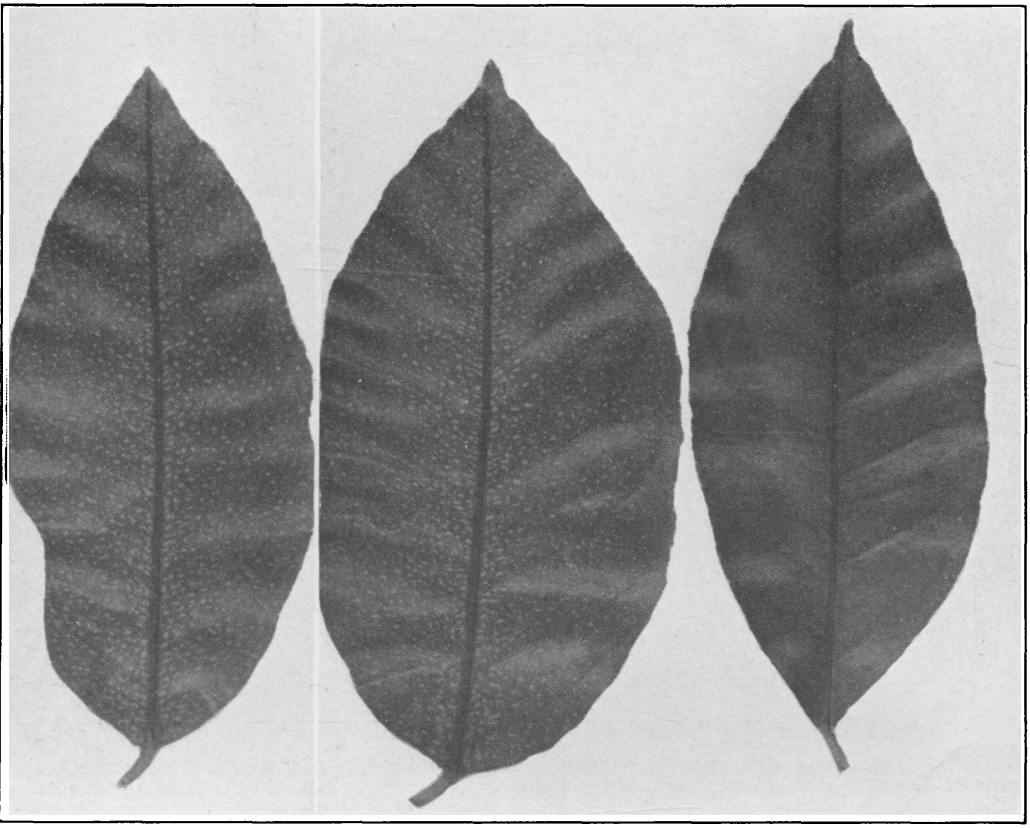

Fig. 1. Eureka-lemon leaves taken from cuttings grown 6 months in a culture solution containing boron, zinc, and purified iron, but no manganese. The leaf on the extreme right was taken from a control cutting that was supplied with manganese; the other two leaves were taken from manganese-deficient cultures.

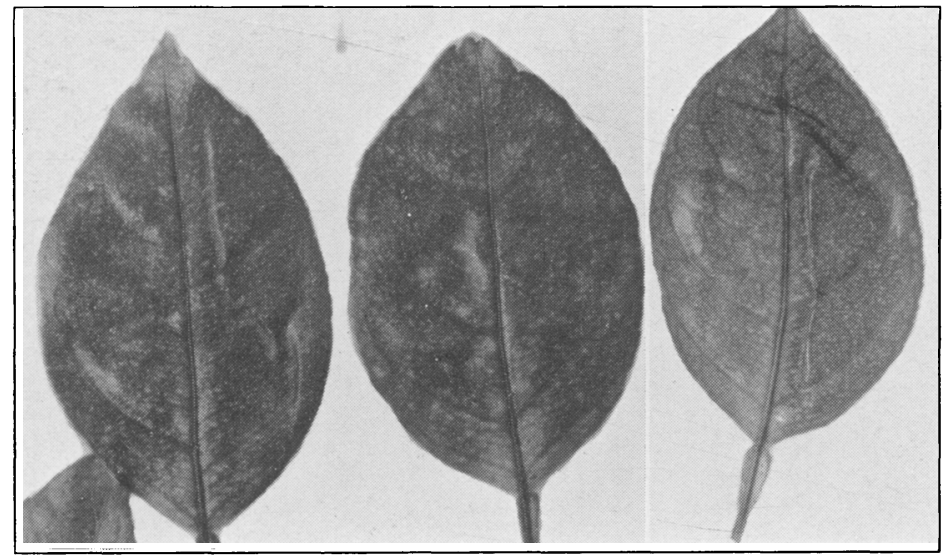

Fig. 2. Young, immature, Valencia-orange leaves from a cutting grown in a culture solution lacking manganese (fig. 14A). The spotting characteristic of a deficiency of manganese is seen in the leaves of both species. 


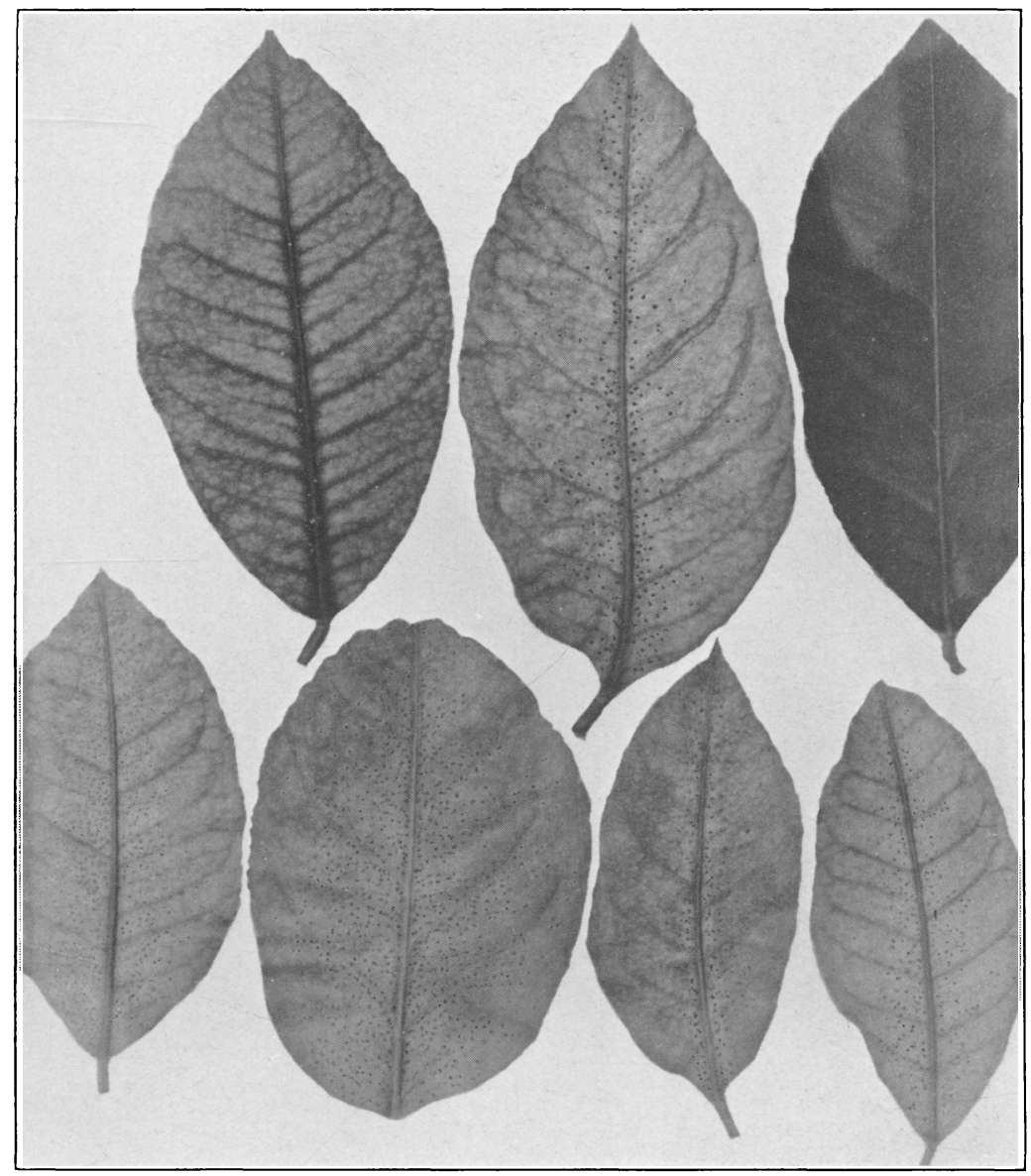

Rough-lemon leaves from cuttings grown 6 months in culture solutions containing boron, zinc, and purified iron, but no manganese. The leaf on the extreme right in the upper row is from a control culture. 


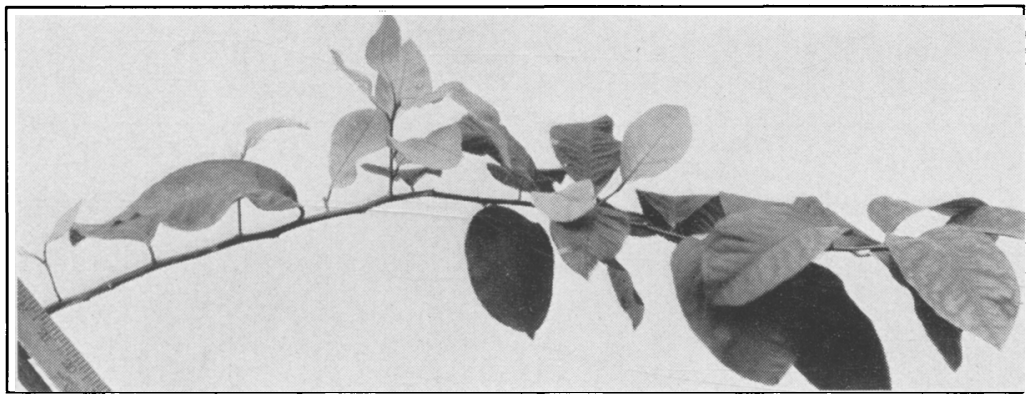

Fig. 1. Typical mature growth of a shoot of a Eureka-lemon cutting grown for 6 months in a culture solution containing boron, zinc, and purified iron, but no manganese.

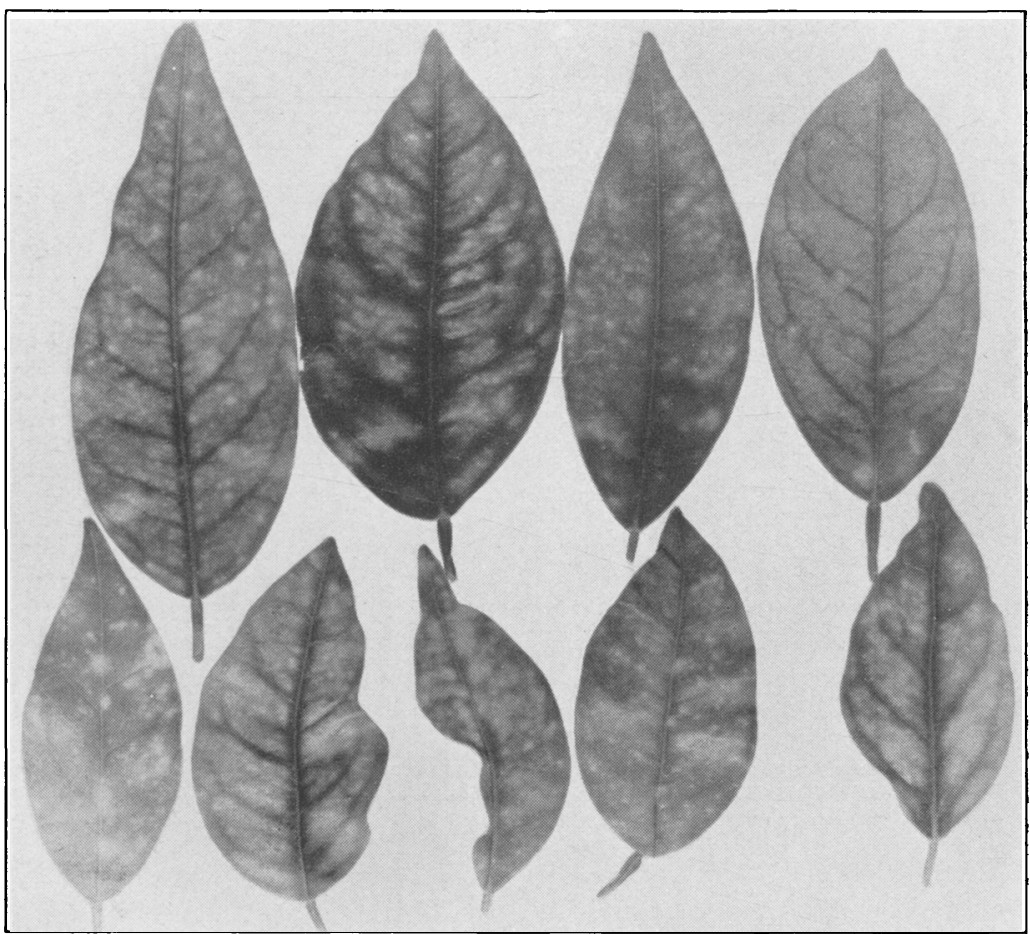

Fig. 2. Leaves of Valencia-orange trees grown in sand cultures containing finely divided calcium sulfate as the source of calcium and to which the other salts of Hoagland's solution were added, except calcium nitrate. The effects shown in the photograph were produced after a 6 months' omission of manganese and iron. 
that attain full size and do not absciss prematurely. In no case do these spots give the leaves a semblance to mottling. Plate 2, figure 1 shows Eureka-lemon leaves taken from cuttings grown 6 months in culture solution containing boron, zinc, and manganese-free iron, but no manganese. The leaf on the extreme right is from a control cutting grown in a

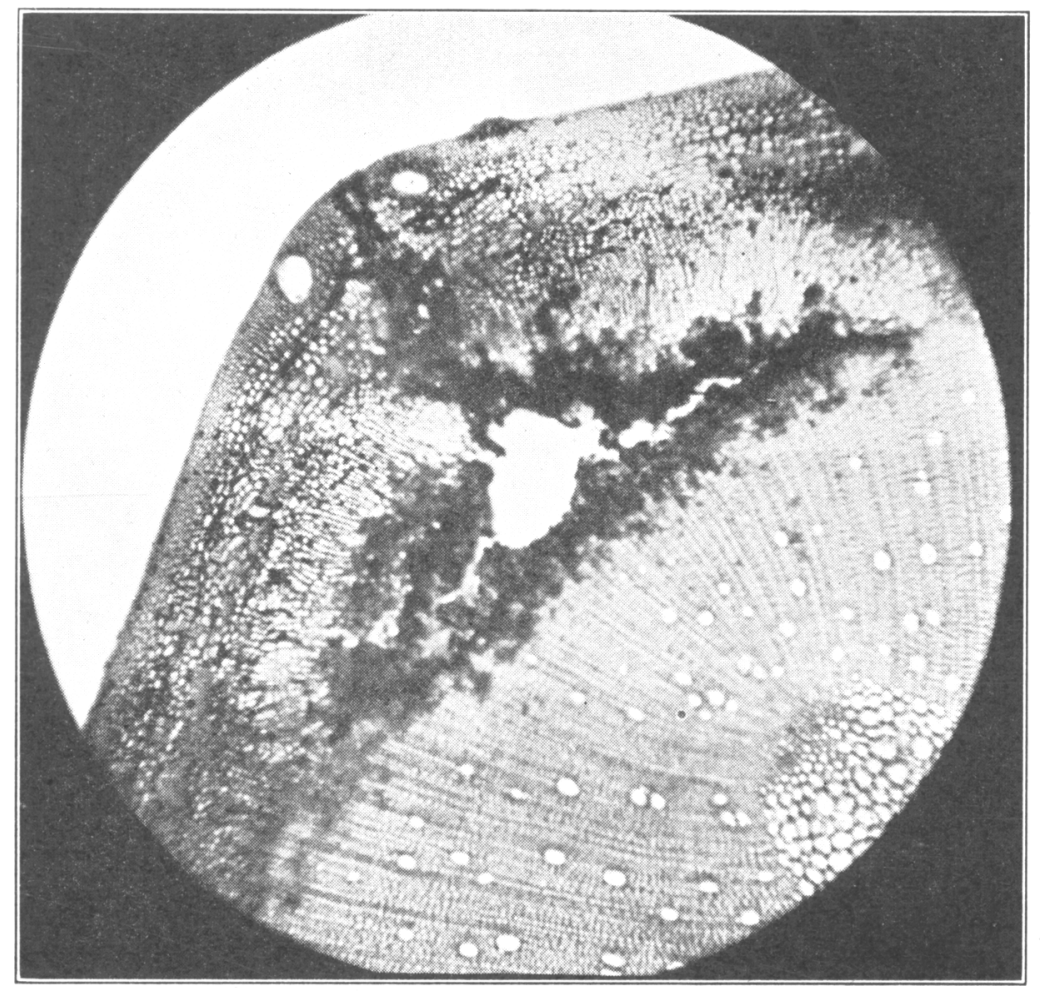

Fig. 10. Cross section of a gum blister on a shoot of a Rough-lemon cutting grown 6 months in a culture solution containing boron, zinc, and purified iron, but no manganese. The section shows the manner in which the gum is exuded from the gum pocket to the surface of the twig.

culture solution containing manganese. The two leaves to the left show the initial stages of manganese deficiency while there was still sufficient manganese available from the previous control culture solution treatment, prior to the present experiment, to enable the leaves to reach full size and maintain a dark-green color. Such leaves may also represent the transitional stage in the resumption of healthy growth when manganese is supplied to cultures suffering acutely from a manganese deficit. 

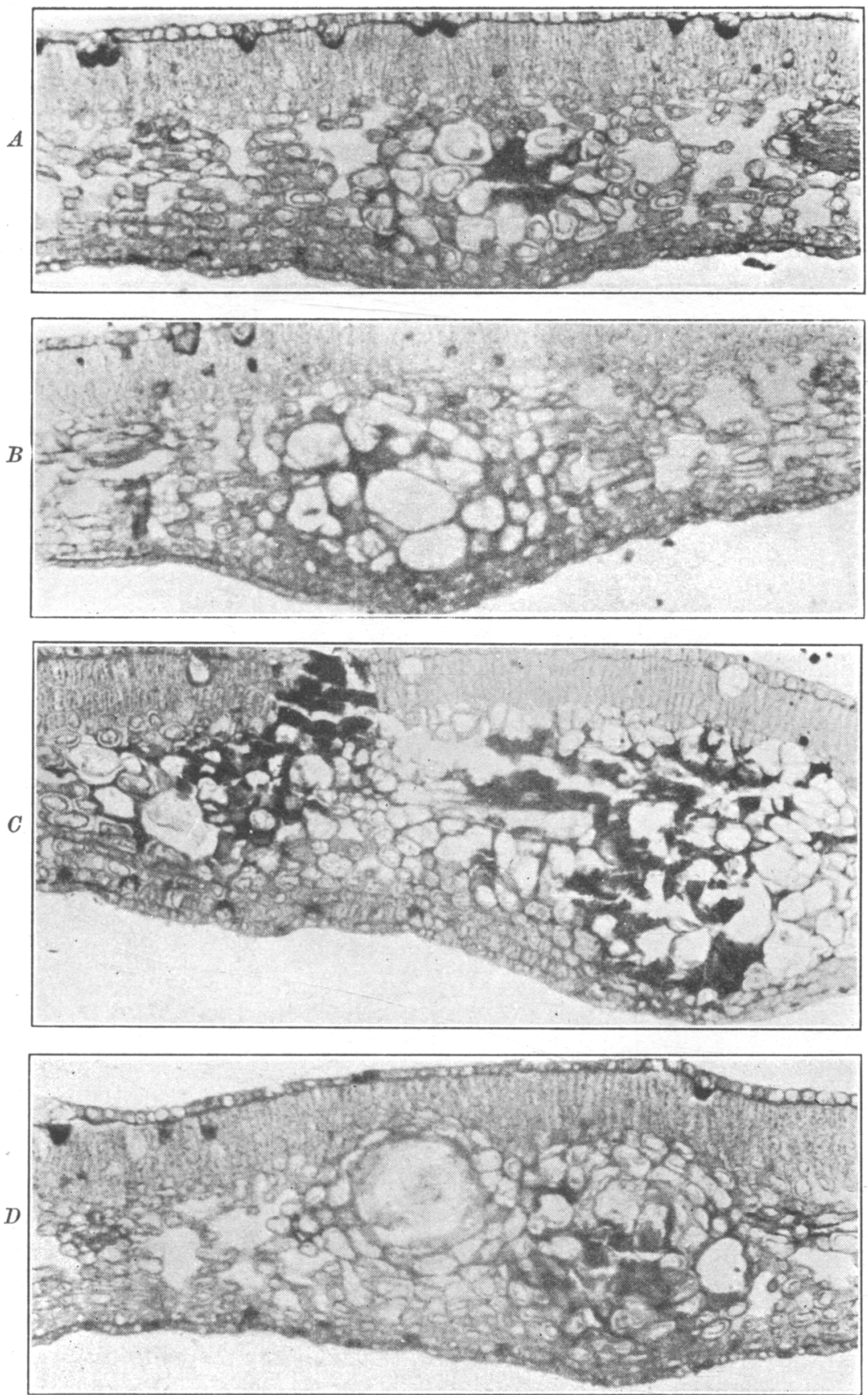

Fig. 11. Vertical sections of lemon leaves from cuttings grown in manganesefree culture solutions: $A$, initial stages of cell enlargement and gum formation in the spongy mesophyll; $B$, advanced stage of cell enlargement; $C$, disintegration of cells and advanced stages of gum formation; $D$, gum formation obviously independent of oil glands. 
It will be seen that a deficiency of manganese has resulted in the formation of spots which are most dense along the midrib. These spots are small circular or elliptical areas which resemble areas invaded by fungi. They may merge and involve the entire tissue between veins (fig. 11). It is of interest that these spots may become corky or resinous,

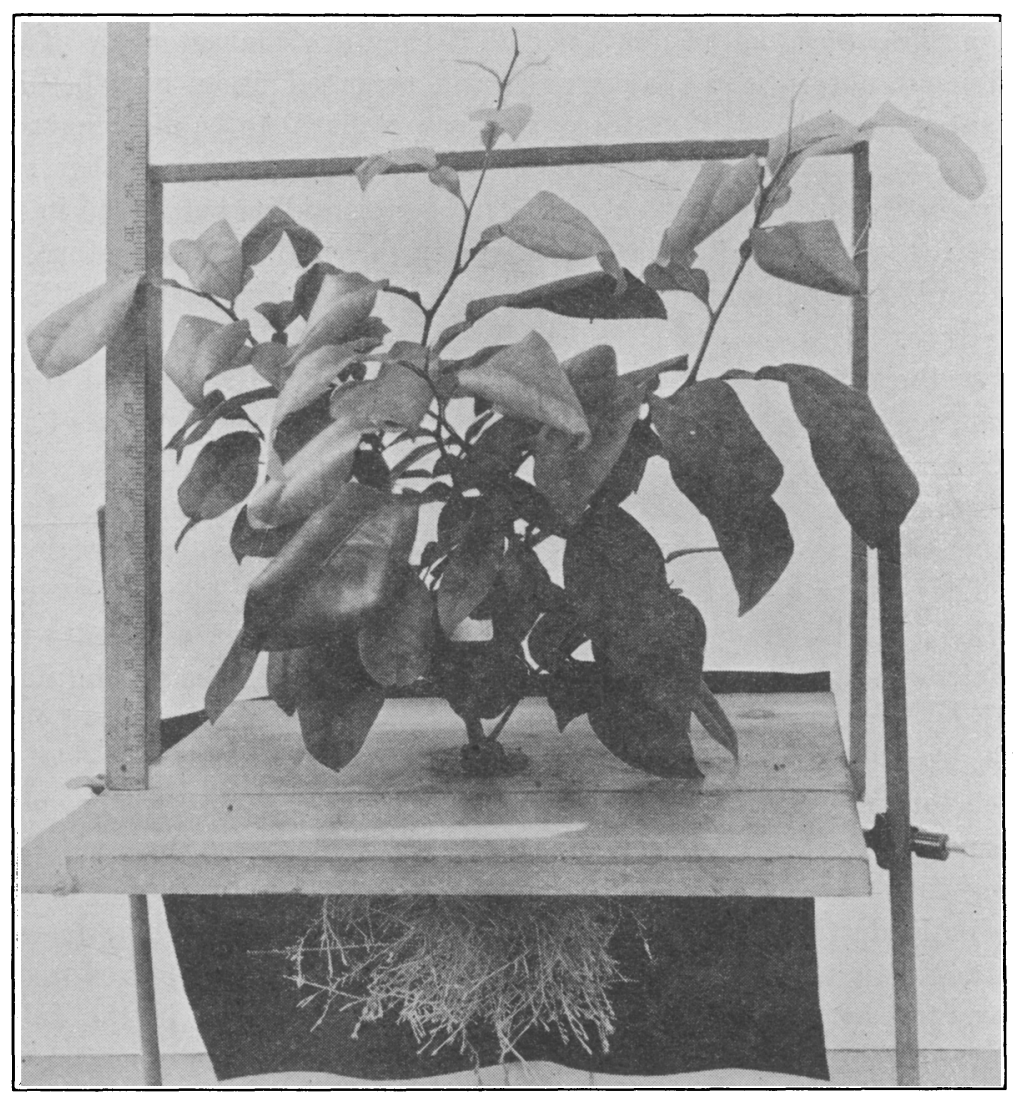

Fig. 12. Sour-orange cutting as a scion on Rough-lemon cutting as a stock grown in culture solution receiving abundant purified iron but no manganese. Compare this with the one shown in figure 13.

or both, on either or both sides of the leaf. Such spots are independent of the oil glands, as may be seen by holding a leaf up to the light, or by making leaf sections. In growing hundreds of lemon cuttings in large pans of culture solution in the past, such spots were often observed but no explanation of their formation was available. They would be present in some leaves and not in others, which now may be explained as due to a shortage in the manganese supply. It occurred largely with 
rapidly growing varieties, and the absence of the spotting was associated with the frequency of the iron-tartrate additions in the distilled water, for the more iron tartrate was added, the more manganese was also added as an impurity in the iron supply. Now such spots may be banished at will by simply increasing the manganese supply.

It is of considerable importance that these spots occur in citrus leaves when manganese is deficient, and that they are characteristic of such deficiency not only in the citrus herein reported upon, but they have recently been found by Skinner and Ruprecht ${ }^{(25)}$ to be also characteristic of manganese deficiency in the leaves of pepper and other truck crops in Florida. No such spots have been found as yet either in mild or severe cases of mottle-leaf of citrus in the field, and, therefore, it is very unlikely that manganese deficiency is related directly to mottle-leaf of citrus.

In the upper row of plate 3, showing the dorsal surface of Roughlemon leaves, the two leaves to the left show advanced stages of manganese deficiency. The spots are very numerous, the leaves are a yellowish-green, and resinous spots occur along the midrib. In the lower row is shown the ventral surface of manganese-deficient leaves.

The nature of these spots is of interest. Figure 11 shows vertical sections of Eureka-lemon leaves taken from cuttings affected with a deficiency of manganese. The spots give the leaf surfaces an undulating outline. Oxalate crystals are visible in the upper epidermis of figure $11 \mathrm{~A}$. An oil gland is shown in $11 \mathrm{D}$ to be independent of the breakdown. The spotting originates from the breakdown of cells first in the spongy mesophyll tissues, especially in the region of very small veins. Other cells become greatly enlarged. The gum formation may proceed through the palisade tissue or through the ventral epidermis. It appears remarkable that such a destructive breakdown of citrus leaves may be prevented by having 0.1 p.p.m. or less of manganese in the culture solution. The results show as conclusively for manganese, as did those of Haas and Klotz ${ }^{(7)}$ for boron, the necessity of minute amounts of these elements for healthy growth.

Effects of Manganese Deficiency on Growth of Orange.-Sourorange cuttings were grown as scions on Rough-lemon cuttings in culture solutions. Figure 12 shows one of these trees after a 6-month period of manganese deficiency. Figure 13 shows another of these trees of similar age in the same culture solution but with manganese present. The writer's hope is that such cuttings may be grown to an even larger size, for with an increase in the size of the plant the difficulties of maintaining a nutrition balance in a culture solution becomes more acute and in overcoming the difficulties much information is gained. 
Without manganese, Valencia-orange cuttings (fig. 14) grew poorly, even though generously supplied with iron. The leaves were chlorotic and the young leaves were spotted, the immature leaves abscissing in

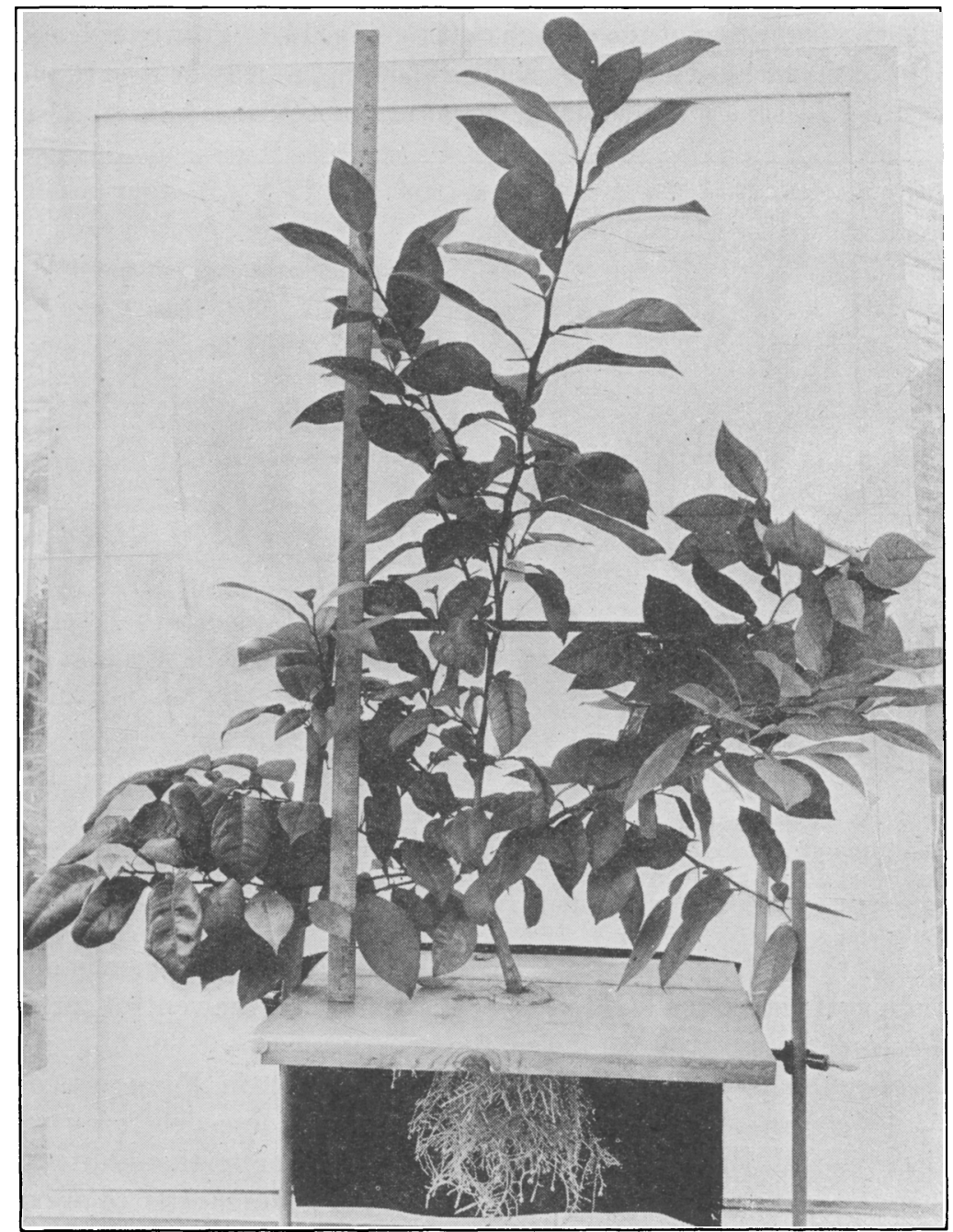

Fig. 13. Sour-orange cutting as a scion on Rough-lemon cutting as a stock, grown in the same culture solution as that used for the plant shown in figure 12, but with manganese added.

extreme cases. Figure $14 \mathrm{~A}$ shows some dying shoots from which the leaves have abscissed. In some cases where manganese-free iron was added to manganese-free cultures containing cuttings of different species, the roots had a rusty-brown color from the iron supplied, and 
yet the leaves were chlorotic. Figure $14 B$ shows the new growth and improved appearance of the cutting shown in figure 14A, 29 days after the first application of manganese. One month later this cutting had new shoots a foot or more in length.

The young leaves of the orange cutting (fig. 14A) grown under conditions of manganese deficiency show a spotting, as may be seen in plate 2 , figure 2. Usually the chlorotic spots are more dense near the basal

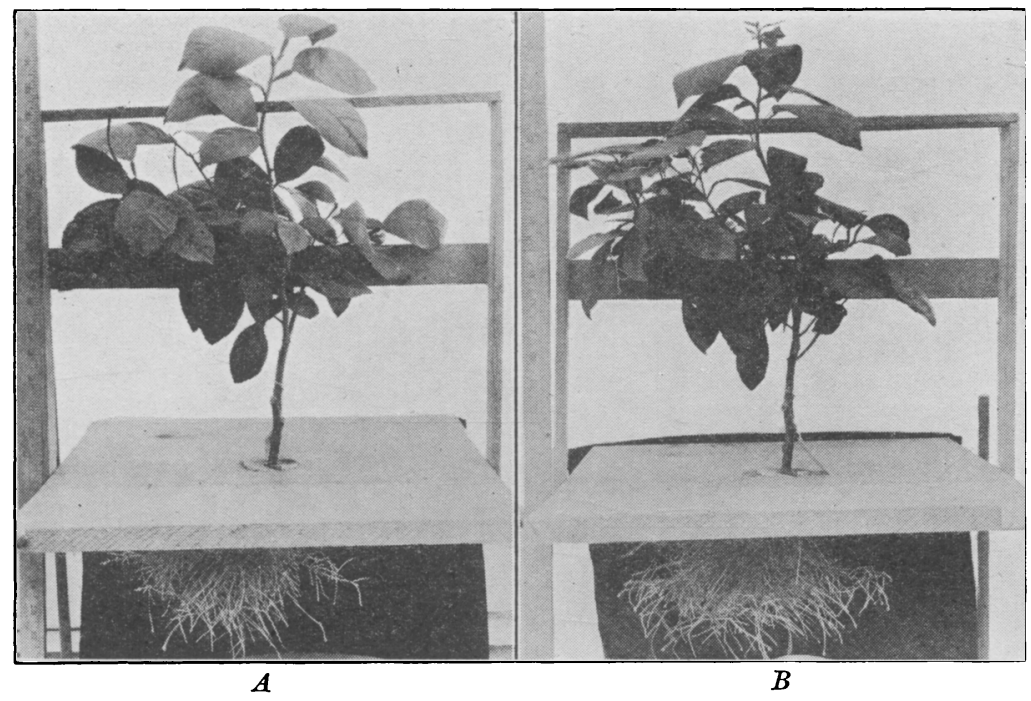

Fig. 14. Valencia-orange cutting as a scion on sour-orange cutting as stock. $A$, Condition of culture on July 6,1931 , after 6 months in manganese-free solution; $B$, condition of culture on August 4, 1931, 29 days after the addition of 5 p.p.m. of manganese as manganese sulfate to the culture solution.

region of the midrib. Sometimes a corking-over of such spots may occur on both surfaces of the leaf but more frequently on the ventral surface. Unless such leaves attain full size, they absciss.

Manganese and Iron Content of Leaves Grown in Manganese-deficient Solutions.-When the symptoms of manganese deficiency were well developed, leaf samples were taken just prior to the addition of manganese. The leaves were powdered in a porcelain mortar to prevent possible iron or manganese contamination from a metal grinder. The ash was determined in order to form an opinion regarding the degree of maturity of the leaves. The manganese was determined according to the procedure of Samuel and Piper, ${ }^{(24)}$ which is based on the periodate method. The iron was determined by the method of Elvehjem and Hart, ${ }^{(4)}$ in which phosphorus was removed and the iron precipitated before estimating the iron colorimetrically with potassium thiocyanate. 
Leaves that were produced after the Eureka-lemon cuttings were grown in solution cultures lacking manganese, contained manganese concentrations ranging from 1.3 to 3.3 p.p.m. of dry matter, while the dark-green leaves that were mature on some of these same cuttings before manganese was omitted (control leaves) contained manganese concentrations ranging from 10.7 to 17.0 p.p.m. of dry matter.

It appears that the leaves of the growth brought to maturity after manganese was omitted from the cultures, were unable to absorb suffcient manganese from the leaves that were produced when manganese was not a limiting factor to bring the plane of manganese nutrition in all leaves on each cutting to the same level. This is in agreement with the appearance of the leaves; dark-green leaves grown and matured under conditions of favorable manganese nutrition do not show symptoms of manganese deficiency at any time after manganese has been made a limiting factor. There appears to be a range below which the manganese content of Eureka-lemon leaves cannot be decreased by new growth that is in need of more manganese.

While the lack of manganese has-not prevented the absorption of iron in the samples deficient in manganese, the iron content is less (averaging 186 p.p.m.) than in healthy green leaves (averaging 274 p.p.m.) of the same cutting.

If Rough-lemon leaf samples from manganese-deficient cultures are examined, it is found that they consist of old yellow leaves deficient in manganese, their manganese content ranging from 1.6 to 3.2 p.p.m. of dry matter. Rough-lemon leaf samples from control cultures consist of dark-green leaves produced before manganese became a limiting factor, and their manganese content ranges from 5.6 to 8.6 p.p.m. of dry matter. It is of interest to note that a Rough-lemon leaf sample taken from one of the most healthy cuttings grown in solution cultures (see fig. 1) that had always had " $A-Y$ " so as to contain 0.1 p.p.m. of manganese, showed a manganese content of 8.5 p.p.m. in the dry matter and is in good agreement with the results from the other Rough-lemon leaf samples. The Rough-lemon leaf samples deficient in manganese show a lower iron content (averaging 182 p.p.m.) than the control leaf samples (averaging 245 p.p.m.).

The manganese and iron content of the leaves of sour-orange cuttings grown as the scion on Rough-lemon cuttings as stock was determined. One sample consisted of manganese-deficient yellow leaves and the other of dark-green leaves collected from the same cuttings but produced before manganese was made deficient. The leaves of the manganesedeficient cultures contained 1.3 and 141.0 p.p.m. of manganese and iron 
respectively in the dry matter, while those of the control sample contained 36.0 and 127.0 p.p.m. respectively. Here the manganese-deficient leaves contained more iron than those leaves that were produced when manganese was not deficient.

When manganese is deficient, in most cases there appears to be less iron accumulated in the leaves. At any rate the leaves have a yellowish cast as though iron were lacking or inactive. In many of these cultures the roots were a rusty brown as a result of the continued supply of

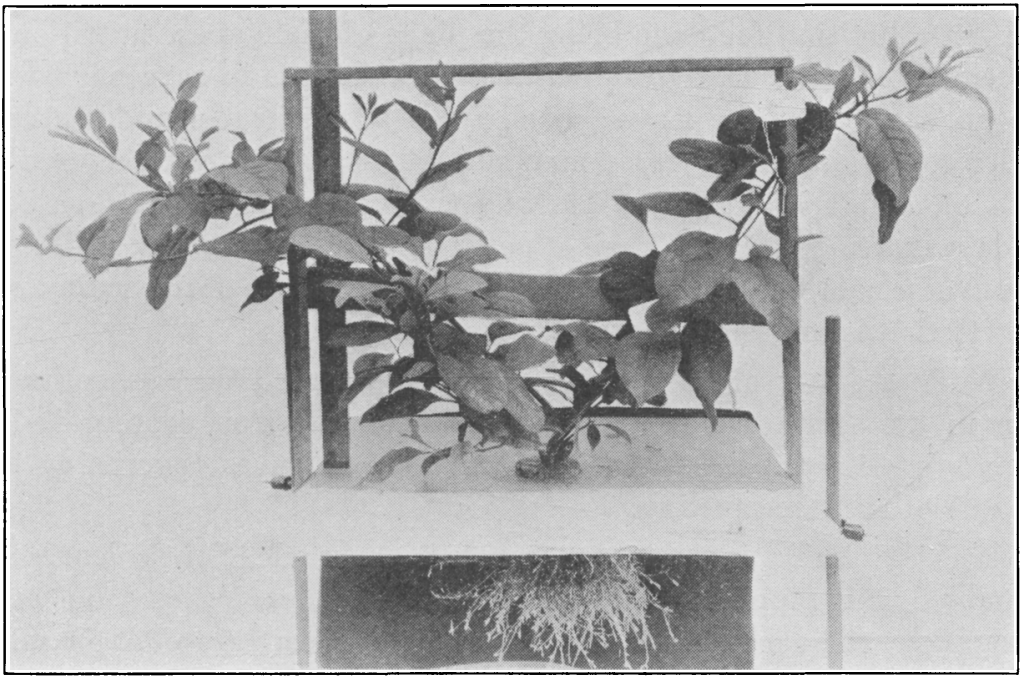

Fig. 15. Rough-lemon cutting grown in a complete nutrient solution for 18 months and then for several months with iron and manganese lacking, which brought about cessation of growth. The addition of manganese initiated vigorous darkgreen growth. As the growth matured, the leaves became full sized, but the ehlorophyll intensity was gradually reduced until chlorosis was evident.

generous amounts of manganese-free iron. Iron does not appear to function properly when manganese is deficient, but it does not require very much manganese to correct this condition, which may be largely a result of a lack of sufficient oxidizing agent within the cells.

Symptoms of Iron Deficiency on Rough Lemon.-The next experiments deal with the lack of iron in the presence of manganese. The plants were grown in a complete nutrient solution for 18 months and then for several months in a nutrient solution lacking both iron and manganese, which caused a cessation of growth. The addition of manganese brought about increased growth within a few days. Figure 15 shows a Rough-lemon cutting in a culture solution containing manganese but no iron. The first young leaves were dark green, owing to 
a small reserve of iron within the cutting as a carryover from the control solution containing iron that was used prior to starting the present experiment. As the leaves increased in size, they became more and more yellowish or chlorotic, the apex of each leaf remaining green the longest. In such cultures the omission of iron has caused the leaves to pass through all of the stages of chlorosis to that of albescence. It is of considerable importance to note that the omission of iron, while bringing about chlorosis and albescence, has not caused mottle-leaf.

Symptoms of Manganese and Iron Deficiencies When Calcium is Supplied as Calcium Sulfate.-If the manganese and iron are both withheld from sand culture of orange trees that have calcium sulfate as their source of calcium, leaves such as those shown in plate 4, figure 2 may be produced. There is an indication of mottling, and in addition the leaves are covered with numerous yellow spots. Subsequent leaves produced may be chlorotic. The spotting appears to be a result of the decreasing manganese available. The mottling may be a composite result of high-sulfate, low-calcium solubility, and a reduced iron supply; it resembles the mottling in lemon leaves on trees grown in sand cultures supplied with iron and manganese but with calcium sulfate as the source of calcium, whereas the leaves are healthy with calcium nitrate as the source of calcium (Haas and Thomas ${ }^{(8)}$ ). Orange trees in sand cultures from which iron alone was omitted simply became more yellow, indicating chlorosis. This was confirmed with cuttings in water culture from which iron was omitted. In qualitatively testing the precipitating power of solutions of the various salts used in Hoagland's solution, it was found that not only phosphates but also sulfates rapidly remove iron from an iron nitrate solution.

\section{SUMMARY}

Manganese is necessary for the healthy growth of citrus cuttings in solution cultures.

Although citrus leaves become yellowish green or chlorotic when manganese is deficient, they do not mottle.

Gum or resinous spots occur on either or both sides of the leaves, their number at first being greatest along the base of the midrib. Oil glands in the leaves show no effect from such a deficiency.

Manganese-deficient leaves in acute stages absciss prematurely and the shoots die back. Such shoots may show a resinous excrescence or gum pockets from which gum may be exuded.

The roots remain healthy in appearance even though manganese is deficient for top growth. This may be because the roots have the first 
opportunity to absorb manganese and do not surrender any considerable part of it to the leaves during a manganese-deficiency period. The quick response of the growth of new green leaves upon adding small concentrations of manganese to the culture solution may be due to the healthy condition of roots in manganése-deficient cultures.

Excessive concentrations of manganese also bring about chlorosis even though iron is added to the culture solution in similarly large amounts.

Iron is essential for healthy growth in citrus; a deficiency brings about chlorosis. When manganese is deficient in citrus leaves, in most cases less iron appears to be accumulated in the leaves. Mottle-leaf of citrus has not been shown to be a result of iron deficiency. Manganese cannot take the place of iron, and conversely iron cannot take the place of manganese. Most, if not all, compounds of iron contain manganese as an impurity. This fact must be considered in any study of manganese deficiency. 


\section{LITERATURE CITED}

1 Bishop, W. B. S.

1928. Distribution of manganese in plants and its importance in plant metabolism. Australian Jour. Exp. Biol. and Med. Sci. 5:125-140.

2 BRYAN, O. C.

1929. The stimulating effect of external applications of copper and manganese on certain chlorotic plants of the Florida Everglades soils. Jour. Am. Soc. Agron. 21:923-933.

3 Clark, N. A., and C. L. Fly.

1930. The rôle of manganese in the nutrition of Lcmna. Plant Physiol. $5: 241-248$.

4 Elvehjem, C. A., and E. B. Hart.

1926. Iron in nutrition. II. Quantitative methods for the determination of iron in biological materials. Jour. Biol. Chem. 67:43-51.

5 Gilbert, B. E., and F. T. MCLean.

1928. A "deficiency disease"': The lack of available manganese in a limeinduced chlorosis. Soil Sei. 26:27-31.

6 HAAS, A. R. C.

1932. Some nutritional aspects in mottle-leaf and other physiological diseases. Hilgardia 6:483-559.

7 HaAs, A. R. C., and L. J. KLOtz.

1931. Some anatomical and physiological changes in Citrus produced by boron deficiency. Hilgardia 5:175-197.

8 HaAs, A. R. C., and E. E. Thomas.

1928. Effect of sulphate on lemon leaves. Bot. Gaz. 86:345-354.

9 Hopkins, E. F.

1930. Necessity and function of manganese in the growth of Chlorella sp. Sci. 72:609-610.

10 Hopkins, E. F.

1931. Manganese and the growth of Lemna minor. Sci. 74:551-552.

11 Ingalls, R. A., and J. W. Shive.

1931. Relation of $\mathrm{H}$-ion concentration of tissue fluids to the distribution of iron in plants. Plant Physiol. 6:103-125.

12 Johnson, M. O.

1924. Manganese chlorosis in pineapples: Its cause and control. Hawaii Agr. Exp. Sta. Bul. 52:1-38.

13 Kelley, W. P.

1914. The function of manganese in plants. Bot. Gaz. 57:213-227.

14 LeE, H. A., and J. S. M.CHARgue.

1928. The effect of a manganese deficiency on the sugar cane plant and its relationship to Pahala blight of sugar cane. Phytopath. 18: 775-786. 
15 MANN, H. B.

1930. Availability of manganese and of iron as affected by applications of calcium and magnesium carbonates to the soil. Soil Sci. 30:117-141.

16 MCGeorge, W. T.

1923. The chlorosis of pineapple plants grown on manganiferous soils. Soil Sci. 16:269-274.

17 McHargue, J. S.

1919. The effect of manganese on the growth of wheat: a source of manganese for agricultural purposes. Jour. Ind. and Eng. Chem. 11:332-335.

18 McHargue, J. S., and R. K. Calfee.

1931. Effect of manganese, copper, and zine on growth and metabolism of Aspergillus flavus and Rhizopus nigricans. Bot. Gaz. 91:183-193.

19 MCHargue, J. S., and O. M. Shedd.

1930. The effect of manganese, copper, zine, boron, and arsenic on the growth of oats. Jour. Am. Soc. Agron. 22:739-746.

20 McLean, F. T.

1927. Feeding plants manganese through the stomata. Sci. 66:487-489.

21 McLean, F. T., and B. E. Gilbert.

1925. Manganese as a cure for a chlorosis of spinach. Sci. 61:636-637.

22 MiLLeR, L. P.

1928. Manganese deficiency in sand cultures. Am. Fertilizer 68:21-22.

23 RICHARDS, MARION B.

1930. Manganese in relation to nutrition. Biochem. Jour. 24:1572-1589.

24 SAMUel, G., and C. S. PiPer.

1929. Manganese as an essential element for plant growth. Ann. Appl. Biol. $16: 493-524$.

25 SKINNER, J. J., and R. W. RUPRECHT.

1930. Fertilizer experiments with truck erops. I. Celery and lettuce on Leon fine sand. II. Tomatoes on calcareous Glade soil. Florida Agr. Exp. Sta. Bul. 218:1-65.

26 WILLIS, L. G.

1928. Response of oats and soy beans to manganese on some Coastal Plain soils. North Carolina Sta. Bul. 257:1-13. 